\title{
Technical Tips for Endovascular Aortic Repair Using the Gore Excluder Abdominal Stent-Graft: Endo-Wedge Technique and Scrum Technique
}

\author{
Tatsuo Banno ${ }^{1}$, Ryoichi Kato ${ }^{1}$, Ryota Hanaoka ${ }^{1}$, Hokuto Akamatsu ${ }^{1}$, Kan Kaneko ${ }^{2}$, Hiroshi \\ Toyama ${ }^{1, *}$ \\ ${ }^{1}$ Department of Radiology, Fujita Health University School of Medicine, Japan \\ ${ }^{2}$ Department of Cardiovascular Surgery, Fujita Health University School of Medicine, Japan
}

\begin{abstract}
When performing endovascular aortic repair (EVAR) procedures, clinicians sometimes encounter cases in which the indications for EVAR are beyond the instruction for use (IFU). In EVAR, proximal neck fixation is the most important factor. This report describes several techniques and tips for EVAR in cases presenting with a difficult short neck or angled neck, especially when using the Gore Excluder ${ }^{\circledR}$. Endo-wedge techniques (EWT), including non-sheathassisted EWT with sheath-assisted strategies, are presented. We describe the scrum technique, which is a special procedure that is only feasible when using the Gore Excluder ${ }^{\circledR}$. In this technique, intentional wire bending around the proximal neck portion occurs by pushing from both sides of the guidewire. This technique is applicable in cases with a sharply angled neck. The scrum with EWT is a more precise strategy for cases with a short or angled neck. Other troublesome cases include limb occlusion caused by weak points in the Gore Excluder ${ }^{\circledR}$ body and legs. The very rare complication of stent-graft collapse is also reviewed.
\end{abstract}

Keywords: Endovascular aortic repair (EVAR), Aortic stent graft, Excluder, Abdominal aortic aneurysm (AAA), Guiding catheter (GC), Endo-wedge technique (EWT), Scrum technique.

\section{INTRODUCTION}

In Japan, over 2000 endovascular aortic repair (EVAR) procedures have been performed using commercial stentgrafts (SGs) to repair abdominal aortic aneurysms. A system has also been established to register operators who are approved to perform or supervise this procedure ("practicing operators" and "instructors"), and the success rate for this procedure is improving. Good results are now being achieved, with few endoleaks, as long as the procedure is performed within the scope of the instructions for use (IFU).

In practice, however, it is necessary to perform EVAR without adhering to the IFU in some patients. In the case of a short neck, sharply angled neck, or poor vessel condition, patients in whom the IFU cannot be followed often require a longer operating time and additional treatment. Problems may also arise unexpectedly, and it is thus important for operators to learn the skills required to deal with these complications. These skills include the use of catheters and guidewires $(\mathrm{GW})$, and proficiency with $\mathrm{GW}$ procedures using the fine 0.014-inch GW rather than the conventional 0.035 -inch GW.

The present report describes tips and techniques for performing EVAR in difficult cases of abdominal aortic

*Address correspondence to this author at the Department of Radiology, Fujita Health University, 1-98, Dengakugakubo, Kutsukake, Toyoake, Aichi,470-1192, Japan; Tel: +81-562-93-9259; Fax: +81-562-95-2253;

E-mail: htoyama@fujita-hu.ac.jp aneurysm (AAA), including cases in which the IFU cannot be followed.

\section{POINTS OF NOTE REGARDING EVAR}

The proximal neck and the landings of both limbs are the most important factors for successful EVAR. Among the various types of endoleak-Ia, Ib, II, III, and IV (except when a Gore Excluder ${ }^{\circledR}$ is used) - type Ia poses the most problems during SG insertion.

The most important factors in preventing type Ia endoleaks are evaluation of the proximal neck and deployment procedures [1]. This report describes a case in which the Gore Excluder ${ }^{\circledR}$ was used. Although the type and characteristics of the SG must be taken into consideration, we omit those details here.

The criterion given in the IFU is that the angle of the proximal neck of the aneurysm is $\leq 60^{\circ}$. The neck must also be $\geq 15 \mathrm{~mm}$ in length. As the Gore Excluder ${ }^{\circledR}$ does not include a proximal bare stent, the angle of the proximal landing is not specified.

However, in many cases in which the neck is $\leq 14 \mathrm{~mm}$ long or is angled, the arterial wall may be shaggy, thrombosed, or dilated. Neck configuration can vary and may be reverse-tapered, dumbbell-shaped, or some other shape that is difficult to treat.

When performing EVAR in such patients with a sharply angled or short neck, it is important to understand the properties and construction of the SG being used. 


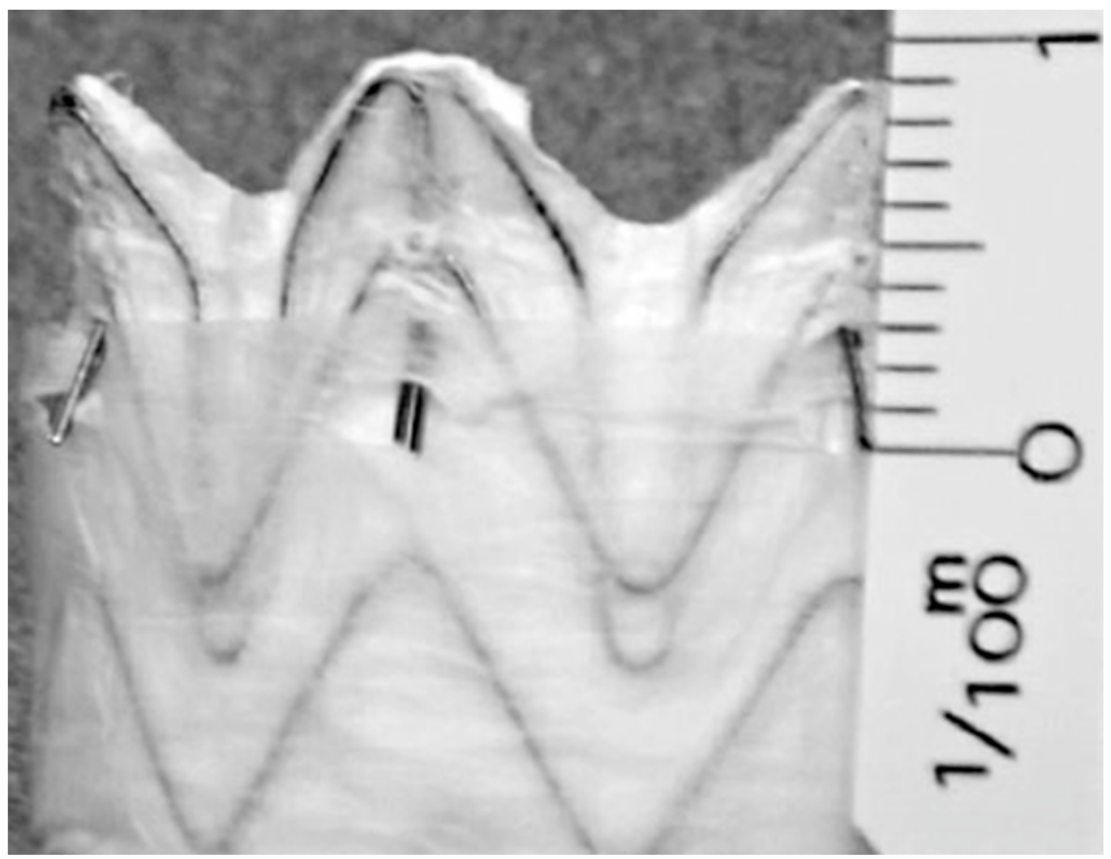

Fig. (1). Proximal portion of the Gore Excluder ${ }^{\circledR}$

Proximal portion of the Gore Excluder ${ }^{\circledR}$ is a flair configuration called a scallop, a wave-like form about 4 mm in height. Barbs are located 9 $\mathrm{mm}$ beneath the top.

Deployment, in particular, demands the use of a variety of techniques to ensure the maximum possible sealing [2-6].

This report explains the features of the Gore Excluder ${ }^{\circledR}$ and offers some technical tips.

\section{FEATURES OF THE PROXIMAL REGION OF THE GORE EXCLUDER $^{\circledR}$ (1)}

The core of the Gore Excluder ${ }^{\circledR}$ consists of a 4-mm wavelike scalloped portion, as shown in Fig. (1). A barb for fixation is located $9 \mathrm{~mm}$ below the tip. The distance from the inferior border of the scalloped portion to the barb is $5 \mathrm{~mm}$. This shape means that the shortest neck length that can be hooked by the barb is $5 \mathrm{~mm}$.

\section{FEATURES OF THE GORE EXCLUDER ${ }^{\circledR}$ (2)}

A number of different types of SG are now in clinical use, but the Gore Excluder ${ }^{\circledR}$ is distinct from other types that have a sheath structure. In contrast to the Gore Excluder ${ }^{\circledR}$, the sheath type SGs cannot be bent in the proximal neck portion.

The "scrum technique" described in this paper cannot be performed with other sheath types SGs, due to the sheath stiffness.

\section{ENDO-WEDGE TECHNIQUE (EWT)}

Because EVAR is used to treat infrarenal AAAs, the proximal sealing length of the SG is an important variable. Ideally, the graft should be positioned directly below the renal artery bifurcation. In patients with a proximal neck of sufficient length, it is not necessary to perform precise landing in the position directly below the renal artery.
However, in patients with a short neck proximal length $\leq 15$ $\mathrm{mm}$ unless even a small sealing zone can be achieved, there is a higher probability of Type Ia endoleak occurring. The EWT is the procedure proposed by Minion et al. for such patients [7]. The use of this procedure with the Gore Excluder ${ }^{\circledR}$ extends the sealing zone by $4 \mathrm{~mm}$ as compared with the standard method.

As shown in Fig. (2A), in this deployment method, a balloon catheter is inserted in the lower renal artery from the brachial approach. The Gore Excluder ${ }^{\circledR}$ is advanced upward so that the balloon fits into the flared area of the SG described above. Fig. (2B) shows a diagram of the endowedge figure. A balloon catheter is inserted in the lower renal artery of the proximal landing area; the scallop configuration of the Gore Excluder ${ }^{\circledR}$ fits the balloon bulging from the orifice of the renal artery. In this manner, proximal sealing length is extended by $4 \mathrm{~mm}$. This gain in the proximal sealing zone enables sealing up to minimally $9 \mathrm{~mm}$ of neck length in short neck cases.

\section{EWT PROCEDURE AND POINTS TO NOTE}

\section{Renal Artery Selection}

During the actual procedure, a guiding catheter (GC) is inserted via the left arm to a site directly above the renal artery. A 5-Fr or 6-Fr GC should be chosen to enable immediate renal artery stenting when the SG incidentally covers the orifice of the renal artery.

Patients with AAA may also have shaggy aorta or irregularities of the renal artery region due to atherosclerotic plaques, and even if a 4-Fr catheter has been used, the nontouch method should be used to select the renal artery. Even if the aorta is tortuous, greater control can be obtained using 


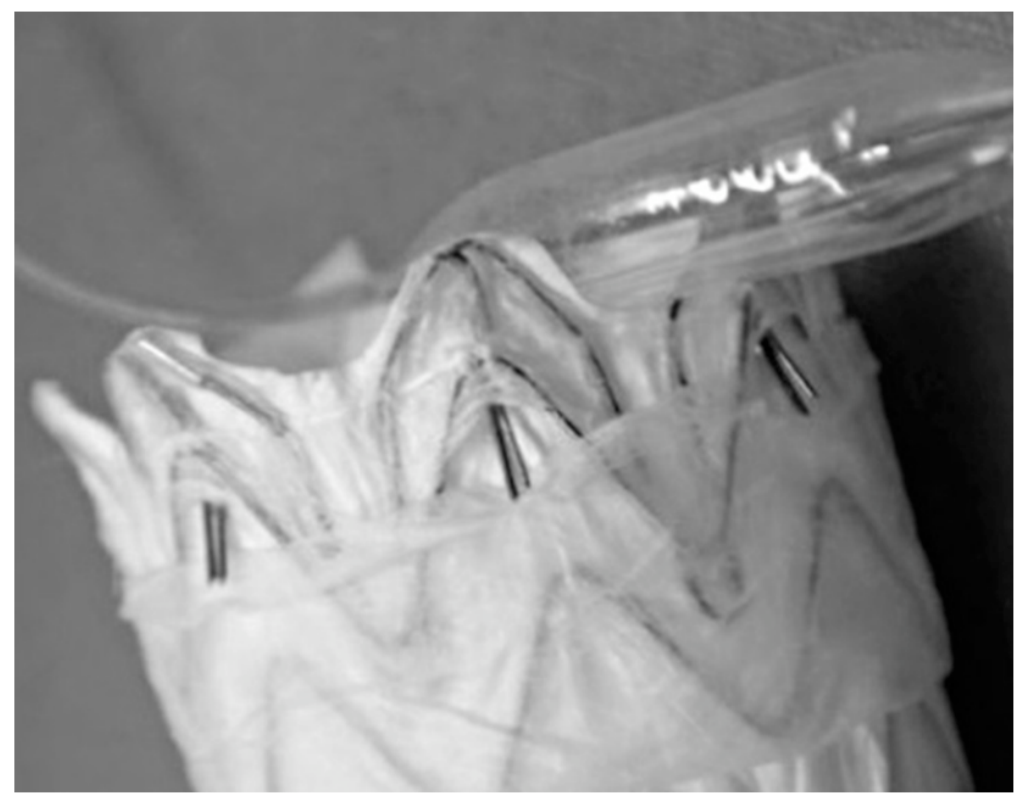

$\mathbf{A}$

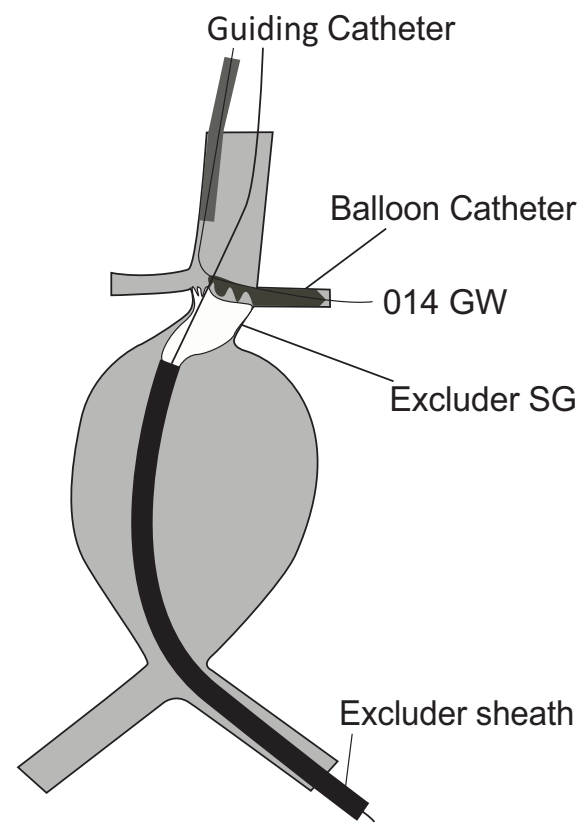

B

Fig. (2). Proximal view of the endo-wedge technique (EWT) with the Gore Excluder ${ }^{\circledR}$

A. Pushing the excluder body to the wedged renal artery balloon catheter, stent-graft (SG) gains 4 mm more length for proximal sealing.

B. Schema of EWT: Micro-balloon catheter is wedged into the lower renal artery along the 0.014-inch guide-wire. Proximal portion of the balloon catheter bulged from the orifice of the renal artery.

the parallel wire technique. Of course, the GW should be 0.014 inches in diameter, and a compatible balloon must also be used. Because a $\mathrm{GC}$ is inserted, a rapid-exchange monorail-type balloon catheter should be placed in the renal artery, and a dilation test should be performed to confirm stability and feasibility of the balloon endo-wedge. If the balloon diameter is smaller than the renal artery, it does not keep the bulging position from the renal artery orifice. So the EWT balloon diameter should be slightly oversized.
This method can also be utilized for the protection of vessels, such as the celiac artery and the superior mesenteric artery.

\section{Deployment Method}

Slow deployment of the Gore Excluder ${ }^{\circledR}$ is performed with a balloon catheter inserted into the lower renal artery, and the balloon is dilated so it bulges into the abdominal aorta, as described above. Two different deployment 


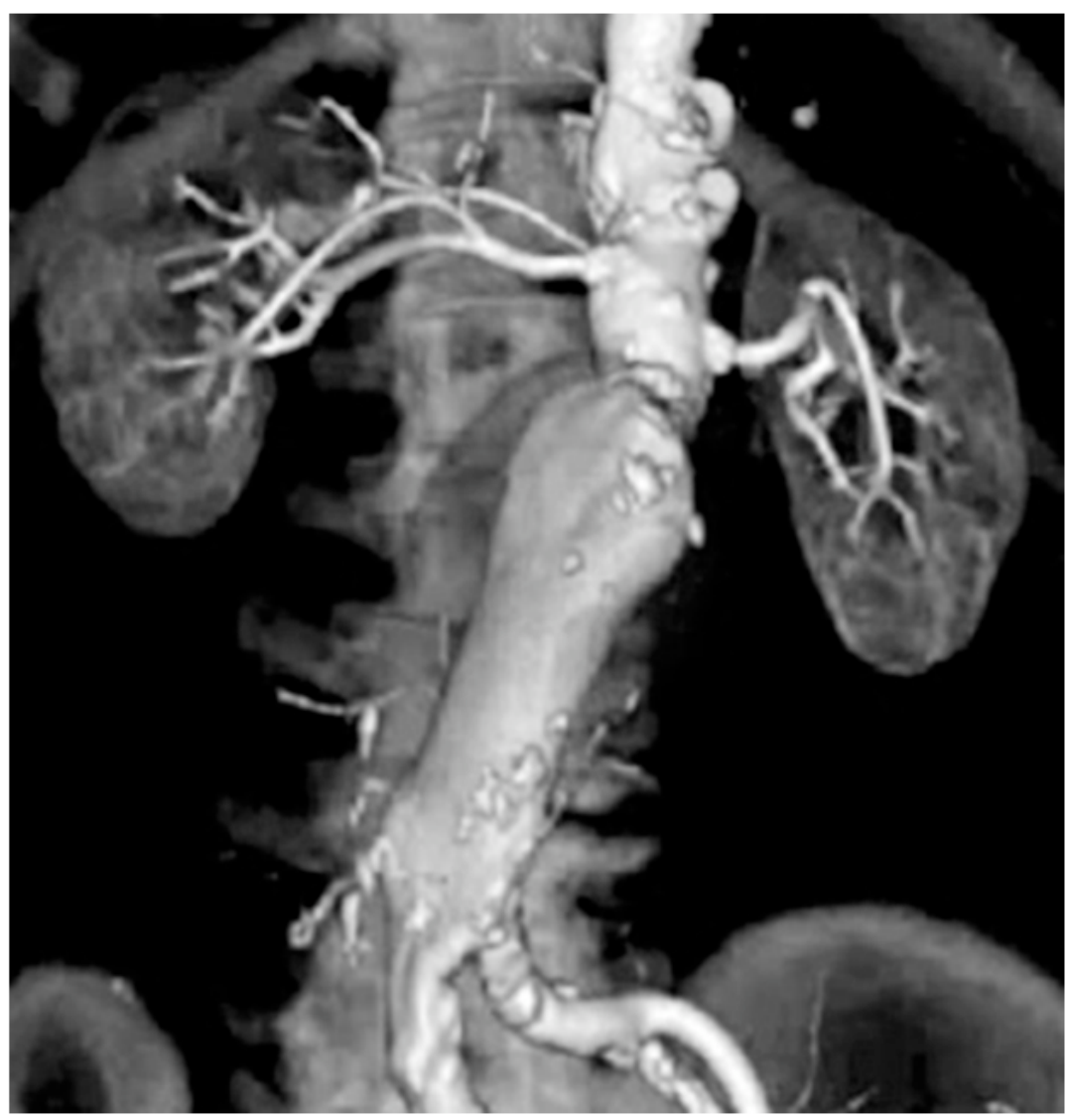

Fig. (3). Endo-wedge technique (EWT), case 2

This abdominal aortic aneurysm (AAA) case shows a short infra-renal neck length.

techniques may be used: either fully unsheathed or slow unsheathing in a sheath-assisted manner. The latter technique is better in this method, as it provides accurate control of the proximal end of the SG, enabling the tip of the scallop to be rotated [8]. This enables deployment in such a way that the SG does not just push against the balloon, but the scallop is still fitted precisely between the balloons.

\section{EWT PATIENTS}

EWT is based on slow deployment, and the sheath-assist method should be regarded as a basic technique whereby the SG is slowly extruded from the sheath without full unsheathing [7].

In the case illustrated in Fig. (3), although the angle was not sharp, the neck from the renal artery was short, and EWT was performed. In this case, slow deployment was performed using the sheath-assist method (Fig. 4A-D). As coverage of the left renal artery was suspected in this patient, a bare metallic stent $\left(\right.$ Palmaz $^{\circledR}$ Genesis TM, Johnson \& Johnson Medical USA) was inserted, and renal arterial blood flow was favorable after the procedure, with no endoleaks (Fig. 5).

\section{SCRUM TECHNIQUE}

We devised the scrum technique based on pull-through of the GW (Fig. 6). For pull-through GW during EVAR, we prefer a GW from the left radial or brachial artery to either the left or right femoral artery. In this case, approximately
$300-400 \mathrm{~cm}$ of $\mathrm{GW}$ is required. We used $400 \mathrm{~cm}$ of the Radifocus stiff-type GW Radifocus, Terumo, Tokyo, Japan. This pull-through method requires the introduction of a long sheath from the brachial artery as far as the femoral artery, to prevent vascular injury by means of the floss effect. We normally use an $85-\mathrm{cm}$ curved sheath for this purpose.

The purpose of the scrum technique is to bend the GW around the proximal neck portion. Pushing from both side of the pull-through $\mathrm{GW}$ causes strong bending around the proximal neck. In some cases, the net force acting on the GW may result in it escaping elsewhere. For example, the GW and upper sheath can escape into the ascending aorta. In this case, the scrum technique cannot be completed. To prevent this GW escape, we use a very stiff GW and a $6-\mathrm{Fr}$ Shuttle sheath (Cook Flexor Tuohy-Borst Sidearm Introducers - Shuttle ${ }^{\circledR}$-SL, USA).

Sometimes, we also use Lunderquist GW (Lunderquist Extra Stiff Guide Wire, Cook Medical, USA) to act as a stiff buddy wire in the descending aortic portion. This enables the SG to be bent by pushing against it from the proximal side, creating an angle in the proximal region of the SG. The deployment site can be also adjusted to ensure that the graft is placed directly below the orifice of the lower renal artery by adjusting the scrum pressure before deployment.

Fig. (7) shows a patient with a sharply angled neck at an angle of $96^{\circ}$. With normal deployment, there would be a high possibility of a proximal endoleak. 


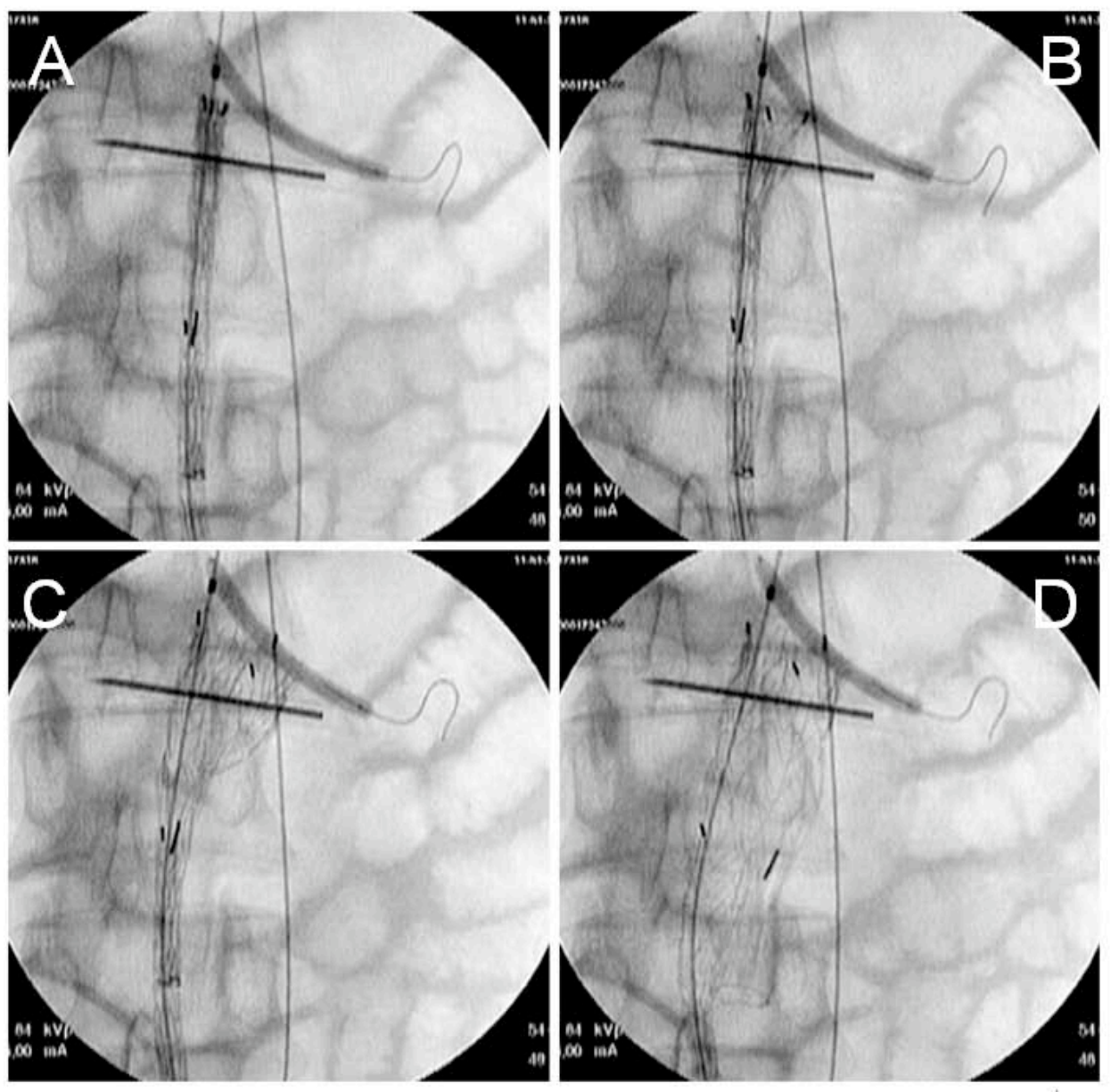

Fig. (4A-D). Endo-wedge technique (EWT) sheath-assisted strategy.

Pushing and rotating the Gore Excluder ${ }^{\circledR}$ onto the renal artery balloon enabled slow deployment without unsheathing, such as is utilized for metal stent deployment.

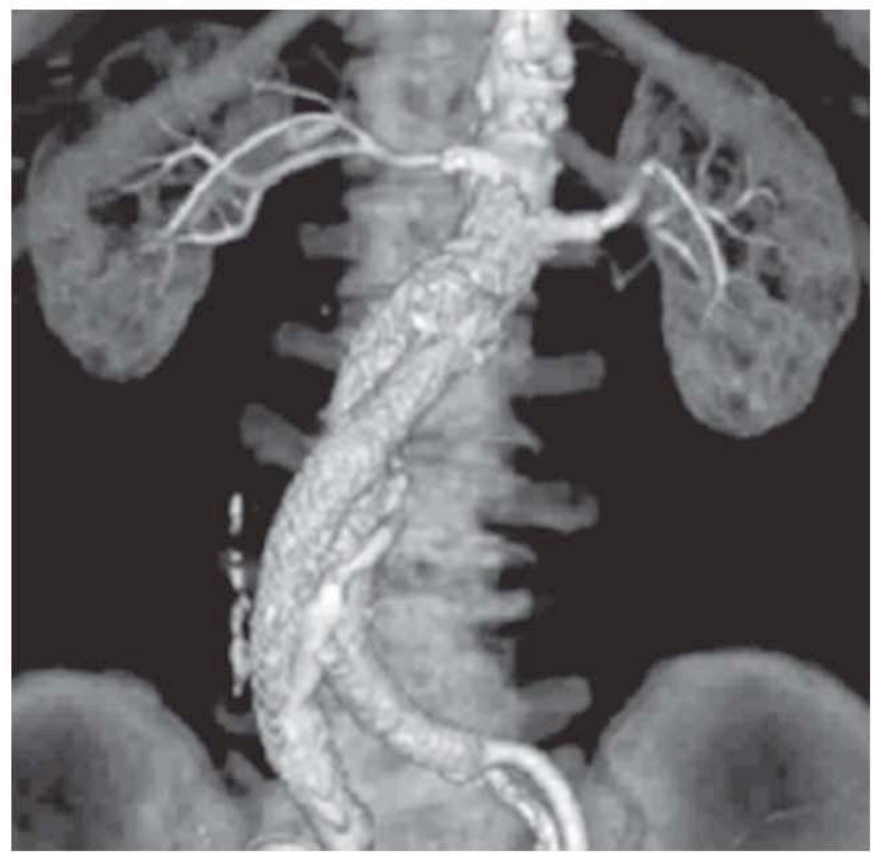

Fig. (5). 3D CT after endovascular aortic repair (EVAR) with endo-wedge technique (EWT).

In this case, coverage of the renal artery was suspected. A Genesis renal artery stent was applied. Guiding catheter was introduced, and stent insertion was straightforward. General image shows small amount of type 2 endoleaks. 


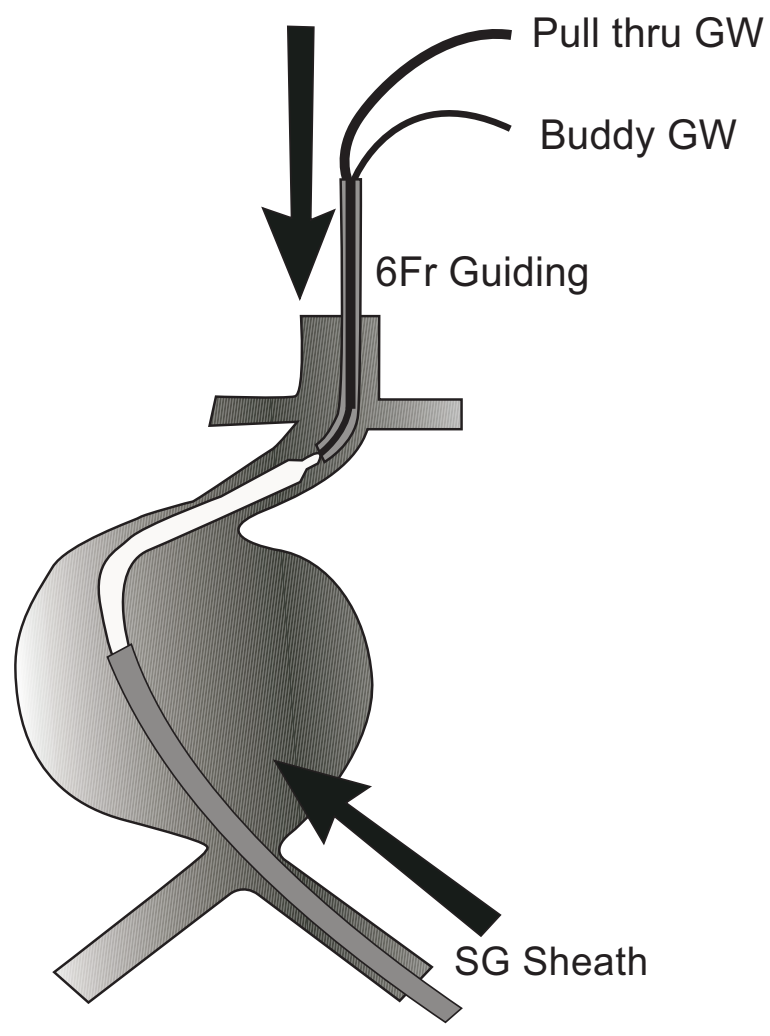

Fig. (6). Scrum technique: very angled neck case

In this case, the neck angle measured 96 degrees.

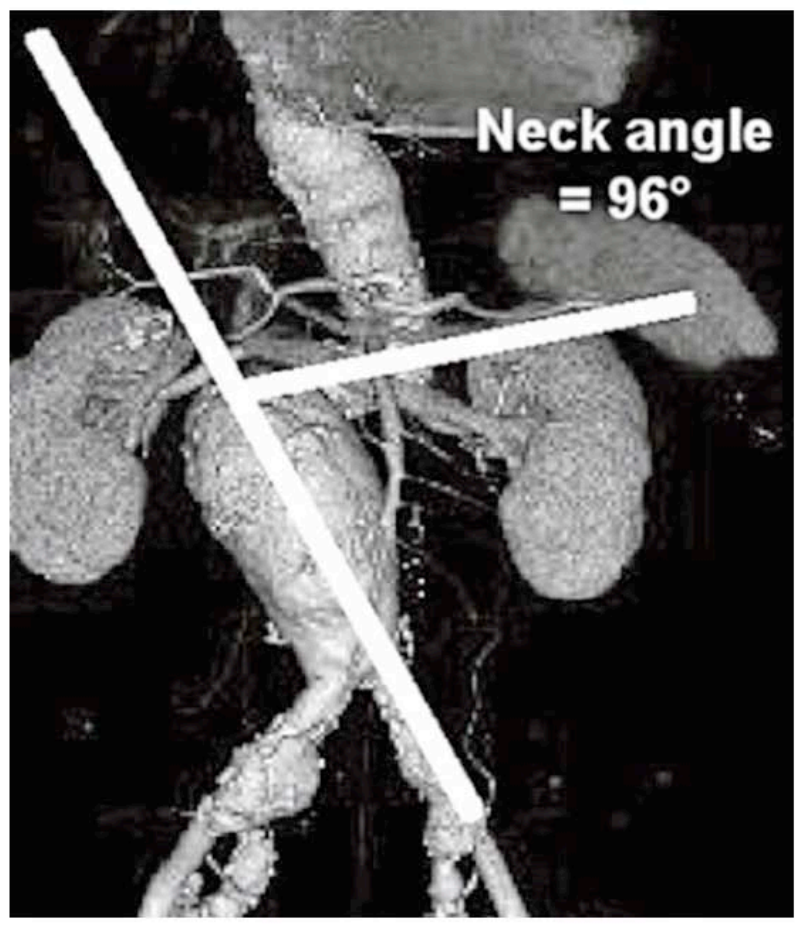

\section{Fig. (7) Scrum technique}

Pushing from both sides of the stent-graft and proximal side in pull-through guide-wire. On the proximal side, the guiding catheter is introduced from a brachial or radial approach. By pushing from both sides, the Gore Excluder ${ }^{\circledR}$ bends strongly around the tip junction. Usually, the stent-graft sheath is advanced above the renal artery, but, in this technique, the sheath tip is advanced within an aneurysmal sac. In cases in which the angle of the pull-through wire from the left subclavian artery is more acute, a stiff buddy wire is needed to strengthen the route. 

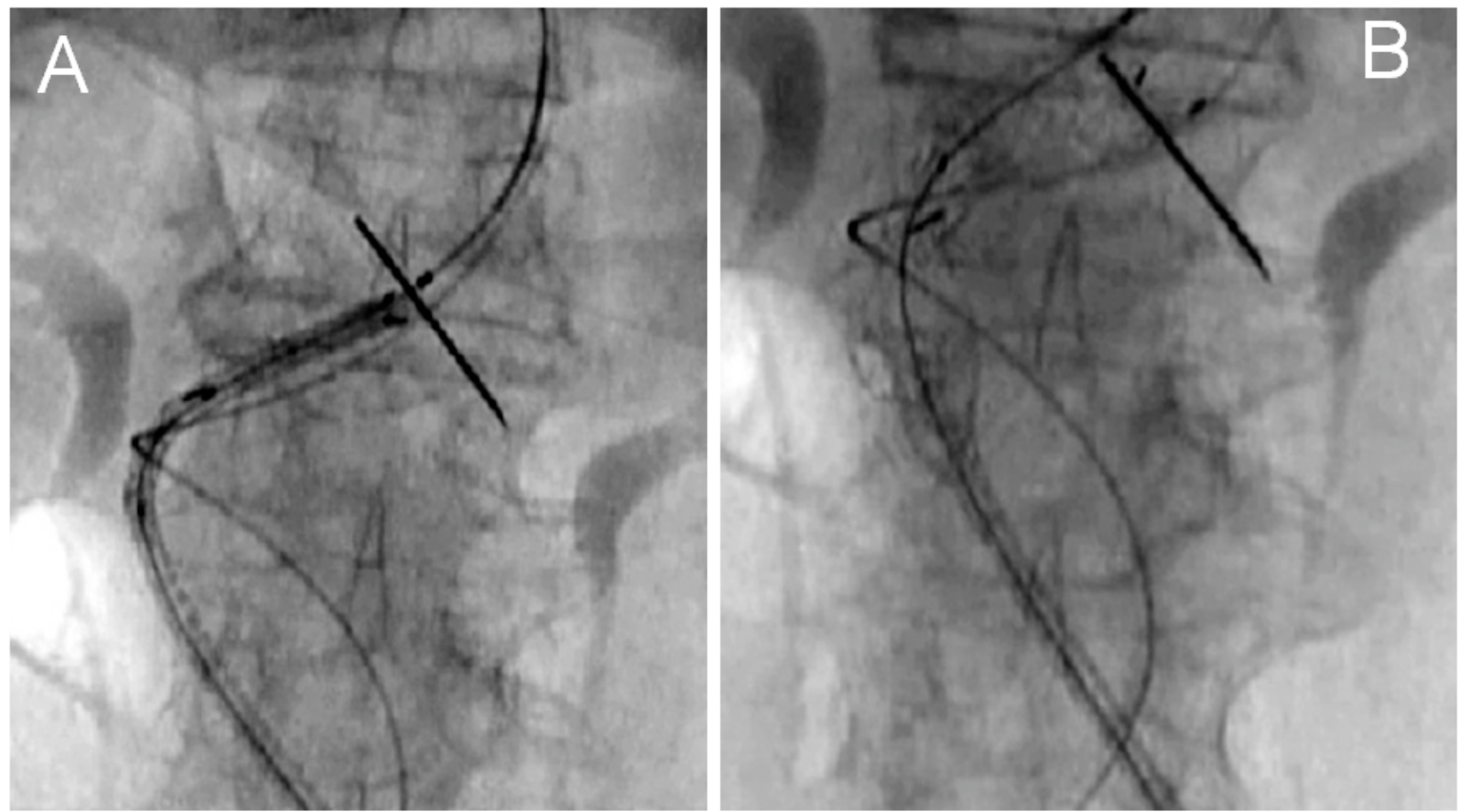

Fig. (8). Scrum technique procedures

A: Very strong stent graft bending is achieved by the "scrum technique" during deployment procedure.

B: After deployment, proximal stent graft shows good conformation around the proximal neck.
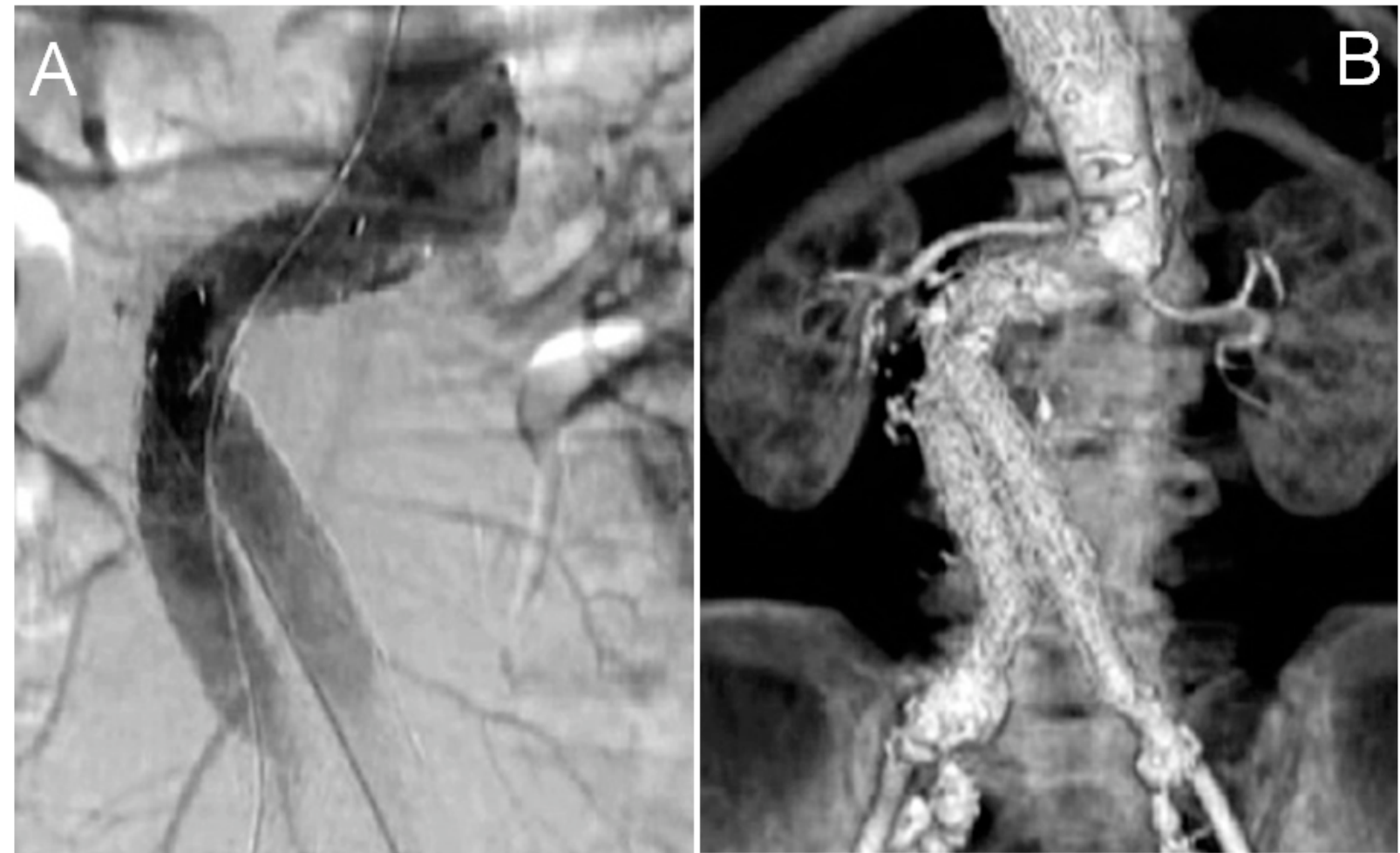

Fig. (9). Scrum technique: digital subtraction angiography (DSA) and 3D-CT image.

A. No endoleaks were observed. The stent-graft was aligned along the proximal neck angle.

B. The stent-graft was kinked at the leg portion, and no flow was present.

Fig. (8A-B) shows deployment by means of the scrum technique, which enabled the SG to be bent sharply by pushing it from both sides. Fig. $(\mathbf{9 A}-\mathbf{B})$ are digital subtraction angiography (DSA) and three-dimensional (3D) images showing the SG aligned with the course of the neck and no evident endoleaks. 

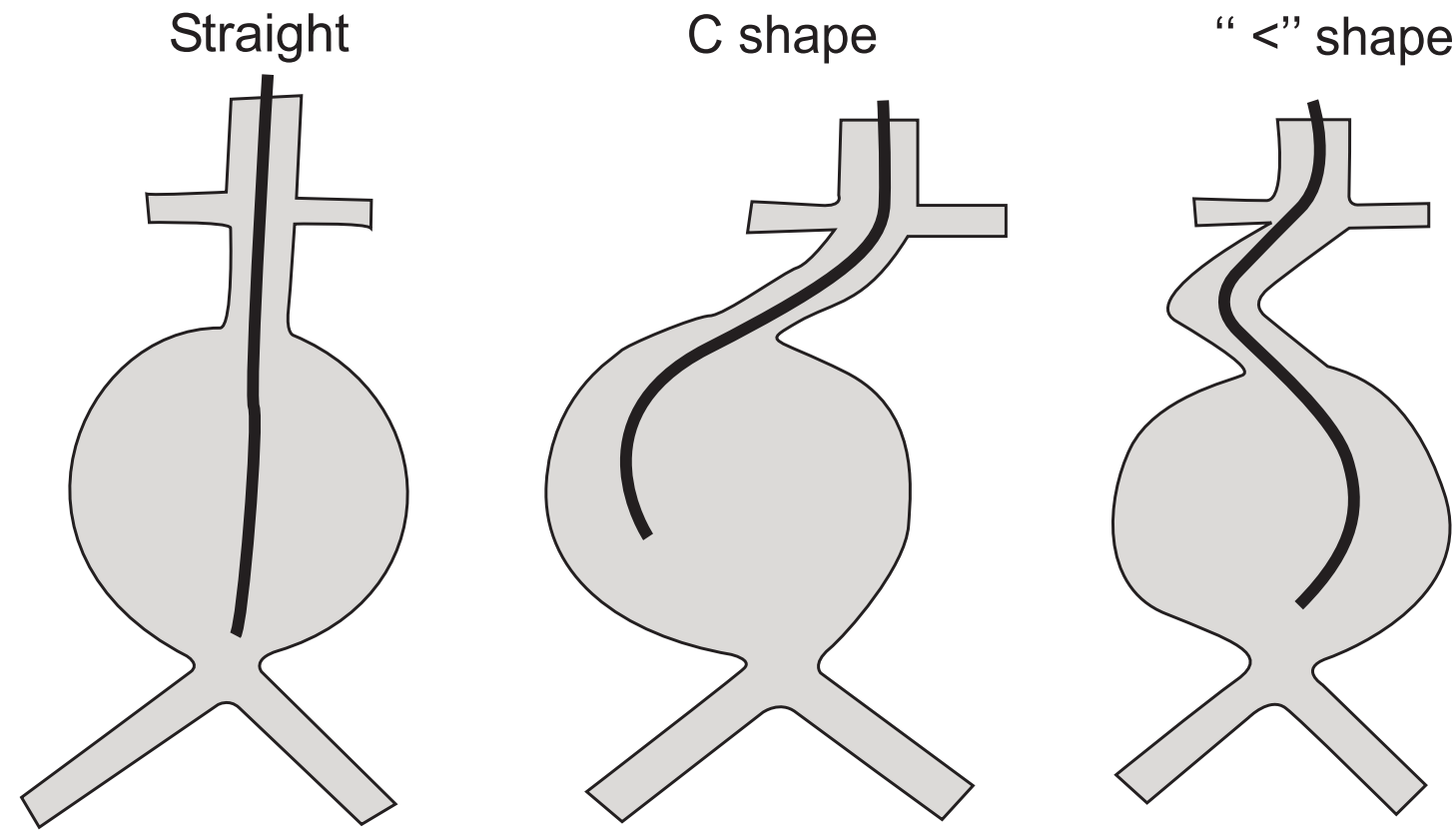

Fig. (10). Indication for scrum technique.

The shape of the angled neck is divided into three types as follows: straight type, C-shaped type, and angled (" $<$ ") type. In these types, the C configuration is appropriate for the scrum technique. In the angle type, the scrum technique is not effective.

In practice, however, the shape of the aneurysm, particularly the shape of the neck, means that the scrum technique can be used easily in some patients but not in others. Our use of the scrum technique had not been successful in some patients. As shown in Fig. (10), the shape of the neck can be classified as straight, C-shaped, or "<" angled (shaped like a "less than" symbol). Of these, the scrum technique can easily be used to create an angle in patients with C-shaped necks. In those with angled necks, however, as shown in Fig. (11), a so-called "bird beak" may be formed in some cases (Fig. 12A-D, 13A-C). In these cases an aortic cuff insertion or Palmaz stent insertion would be needed to eliminate endo-leaks. In such cases, the wirebending technique described below, in which the $\mathrm{GW}$ is bent in advance, is more effective than the scrum technique.

\section{COMBINED SCRUM TECHNIQUE AND EWT}

In the scrum technique, pressure is applied from the proximal side against the advancing SG to determine the site of deployment around the renal artery orifice, but it is difficult to make fine adjustments on the order of a few millimeters. We therefore devised a method of utilizing EWT for scrum deployment by pushing against the balloon in the renal artery.

This method can be used effectively in patients with dilations very close to the renal artery. It has the advantage that, even if the renal artery is covered, a bare stent can be easily inserted to enable recovery.

The patient shown in Fig. (14A-B) has a sharply angled, short neck, and in this case, both the scrum technique and EWT were used together (Fig. 15A-D). Fig. (16A-B) is a postoperative $3 \mathrm{D}-\mathrm{CT}$ image showing good positioning.

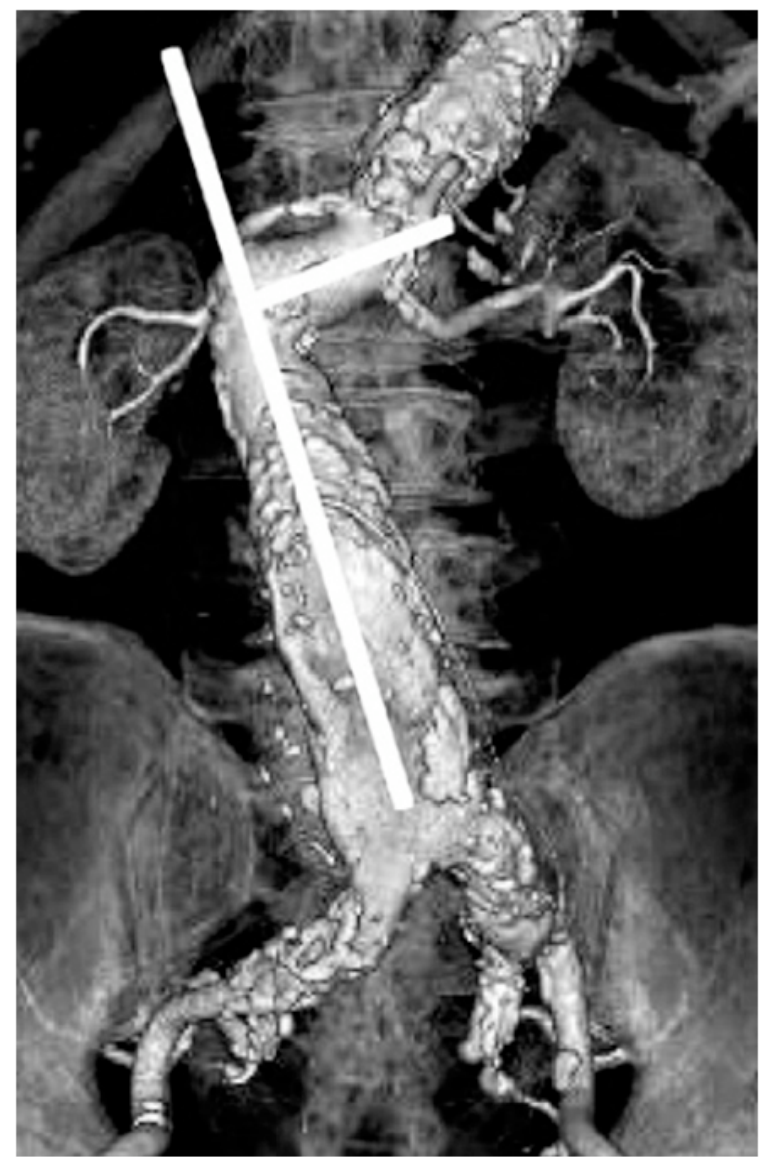

Fig. (11). Ineffective case of scrum technique.

In this case, the angle is 87 degrees. Configuration is angled type, rather than $\mathrm{C}$-shaped type. 

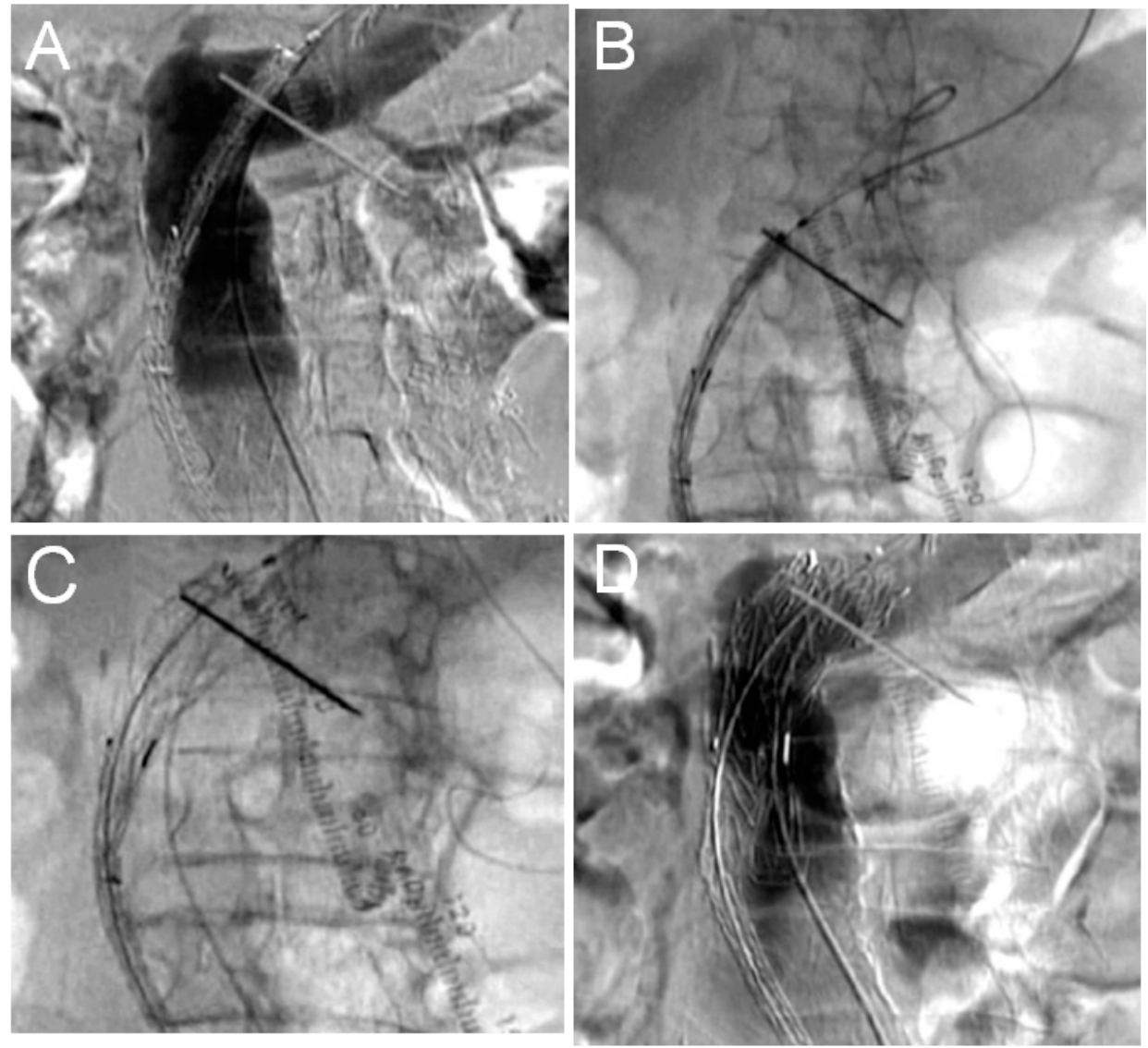

Fig. (12). Scrum technique in angled configuration case.
A. Tips did not bend when pushing each other sides.
B. Deployment was done in a weak-bending configuration.

C. Stent-graft opened without inclining the neck angle.

D. DSA showed type I endoleaks. After balloon touch-ups, the endoleaks disappeared.
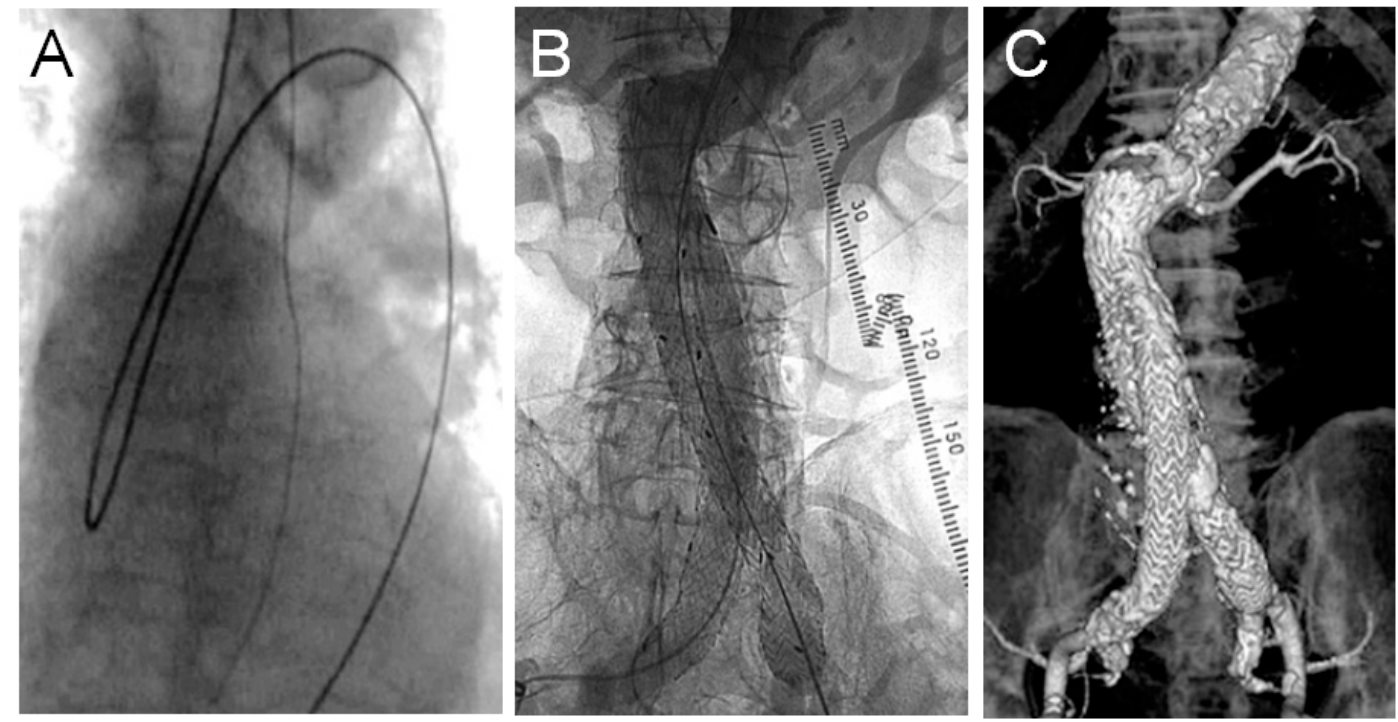

Fig. (13). Cause of ineffective scrum technique case

A. Because of the acute angle, the pushing pressure is diverted into the descending aorta.

B. Final DSA in the case. No endoleaks were found.

C. No endoleaks in postoperative 3D-CT. 


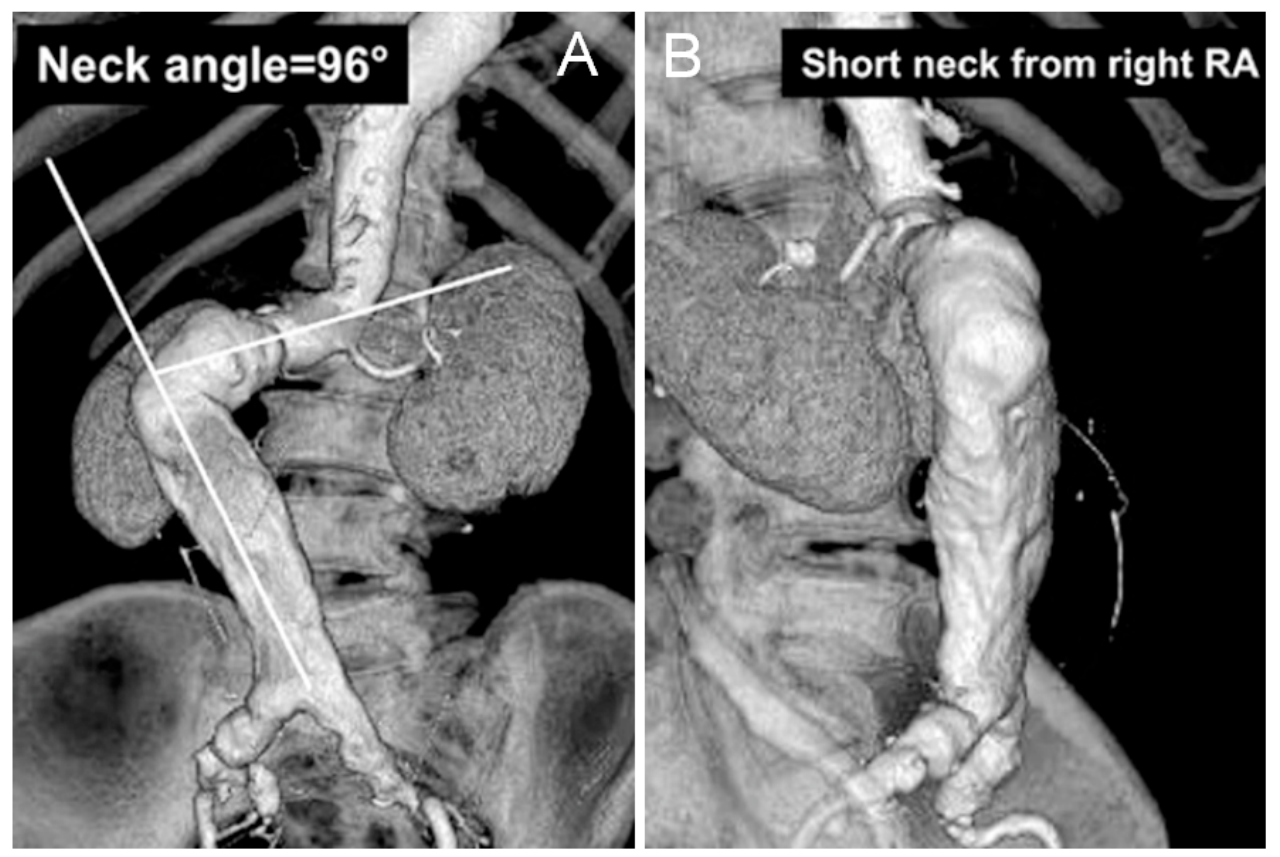

Fig. (14). Scrum technique + endo-wedge technique (EWT).

This abdominal aortic aneurysm (AAA) case shows very strong neck angulation and the neck is very short in the frontal (A) and right anterior oblique (RAO) view (B).
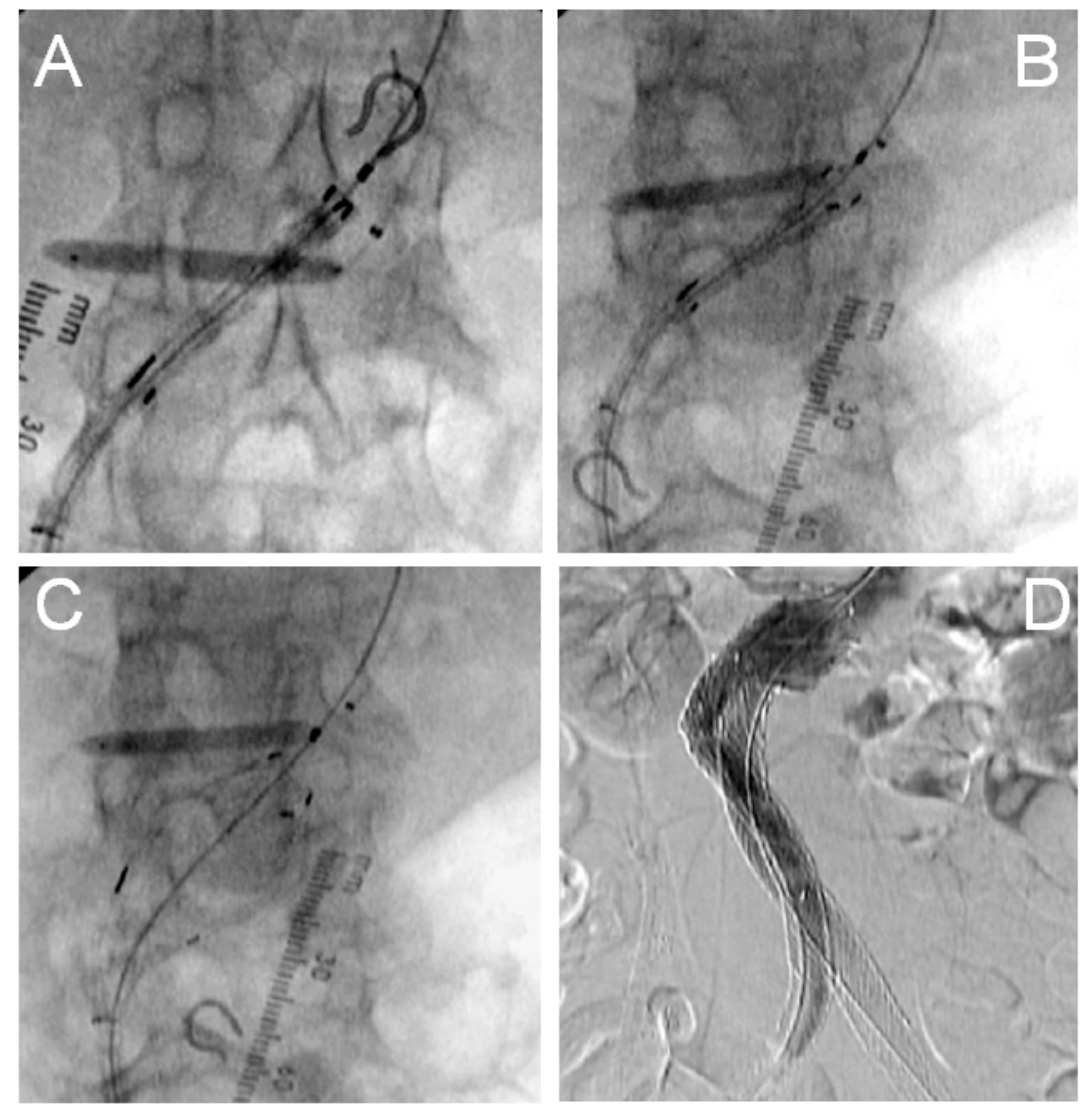

Fig. (15). Scrum technique + endo-wedge technique (EWT)

A. Balloon catheter into right renal artery using a 5-Fr guiding catheter from the brachial artery.

B. Pushing each other in a scrum technique fashion.

C. Deployment: non-sheath-assist strategy caused slight distal migration in deployment.

D. Final DSA does not show any endoleaks. Well-configured deployment along the neck shape. 

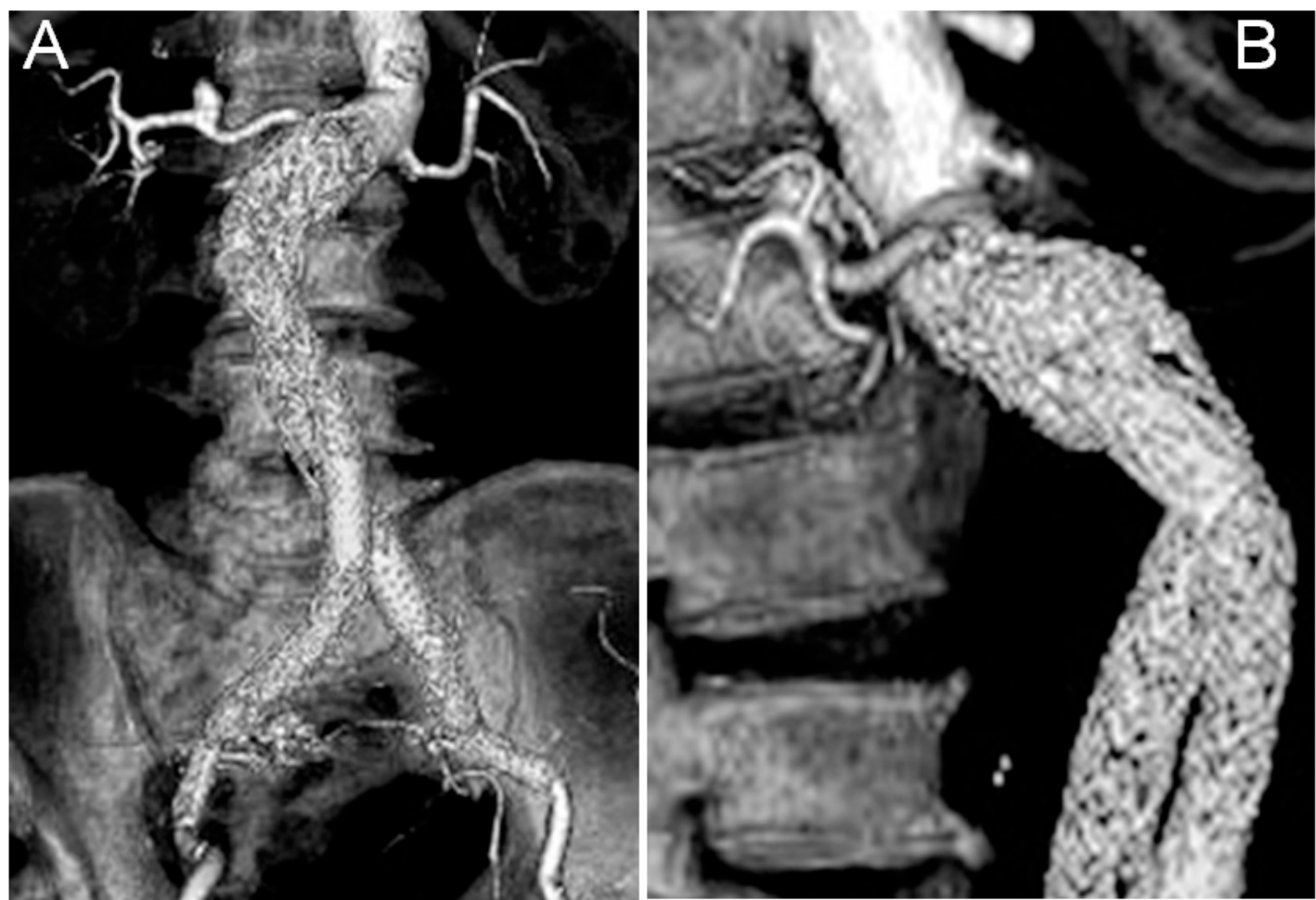

Fig.(16).Postoperative 3D-CT of scrum and endo-wedge technique (EWT).

A. 3D-CT does not show any endoleaks. Bare stents were applied in both legs.

B. Stent-graft tip is not acute from the renal artery, but sealing was good.
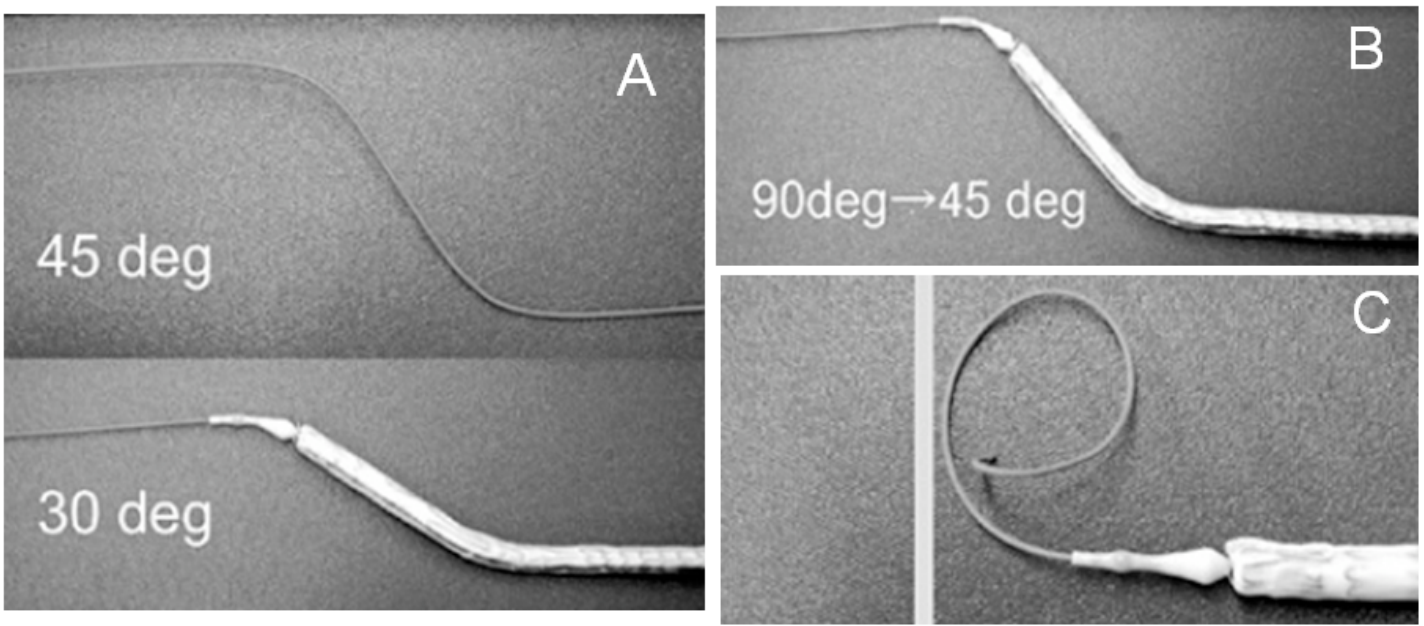

Fig. (17). Wire bend technique.

A: Using a 45-degree bent Lunderquist guide-wire, the Gore Excluder ${ }^{\circledR}$ will bend slightly at a reduced angle of 30 degrees.

B: 90-degree bent Lunderquist GW. The stent-graft will bend 45 degrees.

C: In the case of a shaggy descending aorta, pig-tail configuration of bending reduces vascular injuries.

\section{WIRE-BENDING TECHNIQUE}

We have described the EWT and the scrum technique, but patients with abdominal aorta may also present with shaggy descending aorta or severe atherosclerotic plaque. In such cases, the risk of thromboembolism if the pull-through method or EWT are used, cannot be ignored. In so-called "shaggy patients," we have devised and are employing a method that avoids touching the descending aorta as much as possible.
In patients with shaggy descending aortas, every effort must be made to avoid advancing the GW, catheter, and SG dilator tip into this area. In such patients, the proximal neck may also be sharply angled, and in this case, the tip of a Lunderquist $\mathrm{GW}$ is bent into the pigtail shape shown in the bottom image of Fig. (17A-C), and the wire is not lifted into the descending aorta if this is at all possible.

Wire bending has been suggested as one technique for bending the proximal neck [9], and we use a method that 

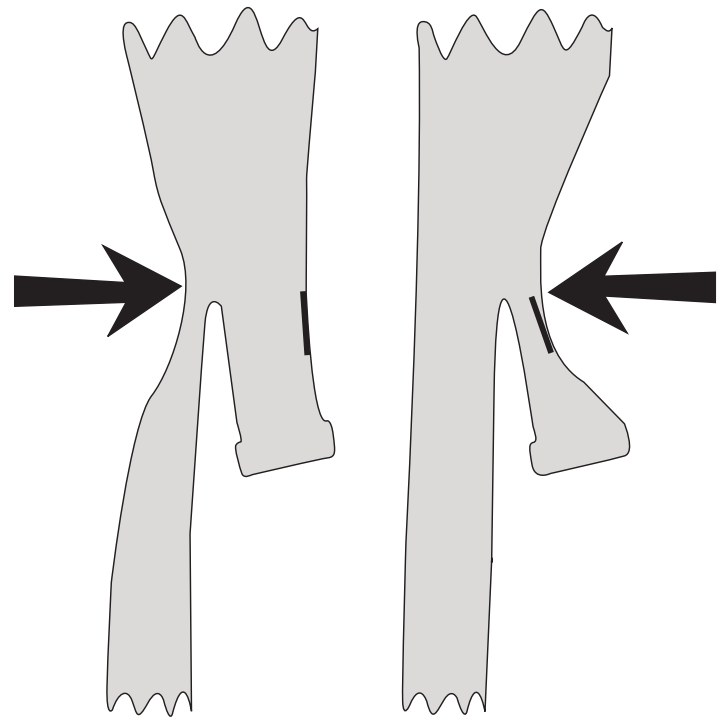

$\mathbf{A}$
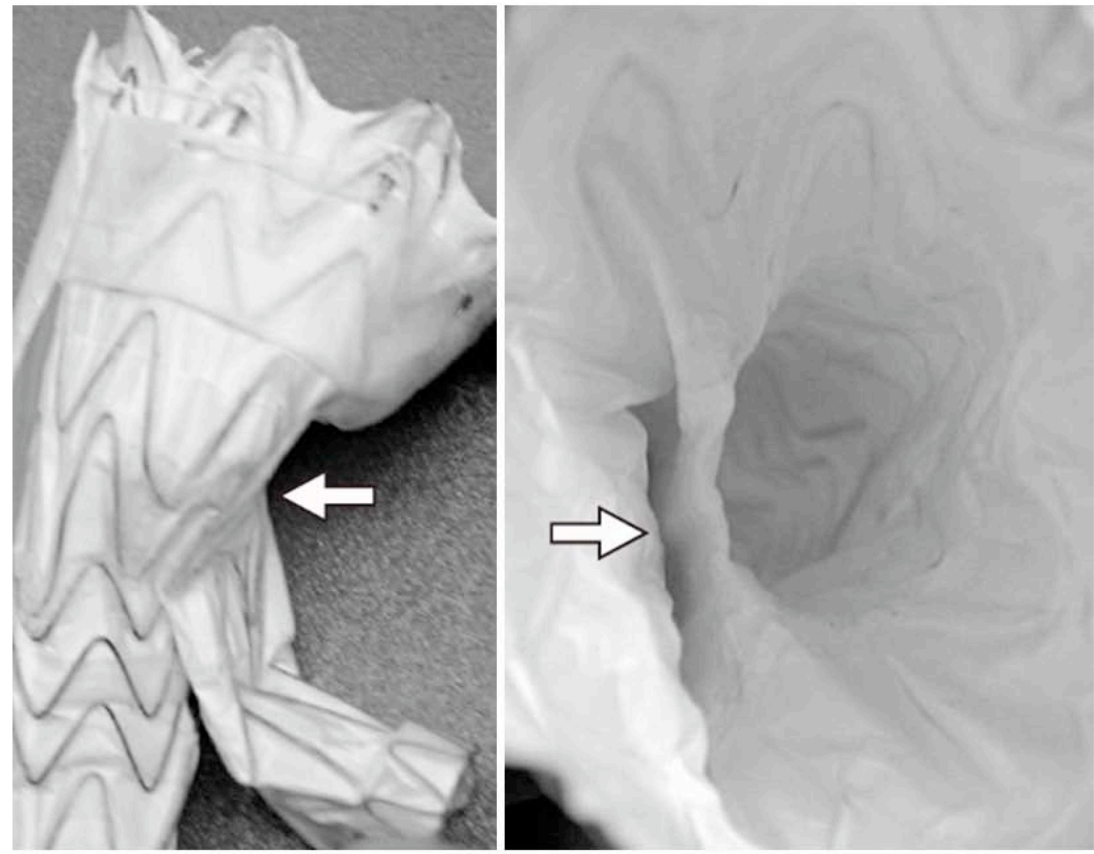

B

Fig. (18). Limb occlusion

A. The Gore Excluder ${ }^{\circledR}$ tends to narrow around the leg portion when pressure or bending force is applied.

B. Picture shows a narrowing in each leg (arrowheads). In some cases, severe occlusion occurs with difficult wire advancement. In such cases, 0.014-inch CTO guide-wires with heavy tips are used.

involves bending the tip of a Lunderquist GW to align it with the angle of the neck in order to improve graft adhesion. The bending process is shown in Fig. (17A). At this point, it is key to bend the GW into a sharper angle than the actual angle.

\section{PROBLEMATIC CASES}

One benefit of the Gore Excluder ${ }^{\circledR}$ is that the SG itself has non-sheath structure that can be bent to a great extent.
This is what makes the scrum and scrum plus EWT techniques described above so effective. In patients with angled necks and others, however, problems such as limb occlusion or SG collapse may occur, and caution is therefore required [10].

\section{LIMB OCCLUSION}

As shown in Fig. (18A-B), in patients with angled necks, occlusion may occur if the contralateral limb or the limb 

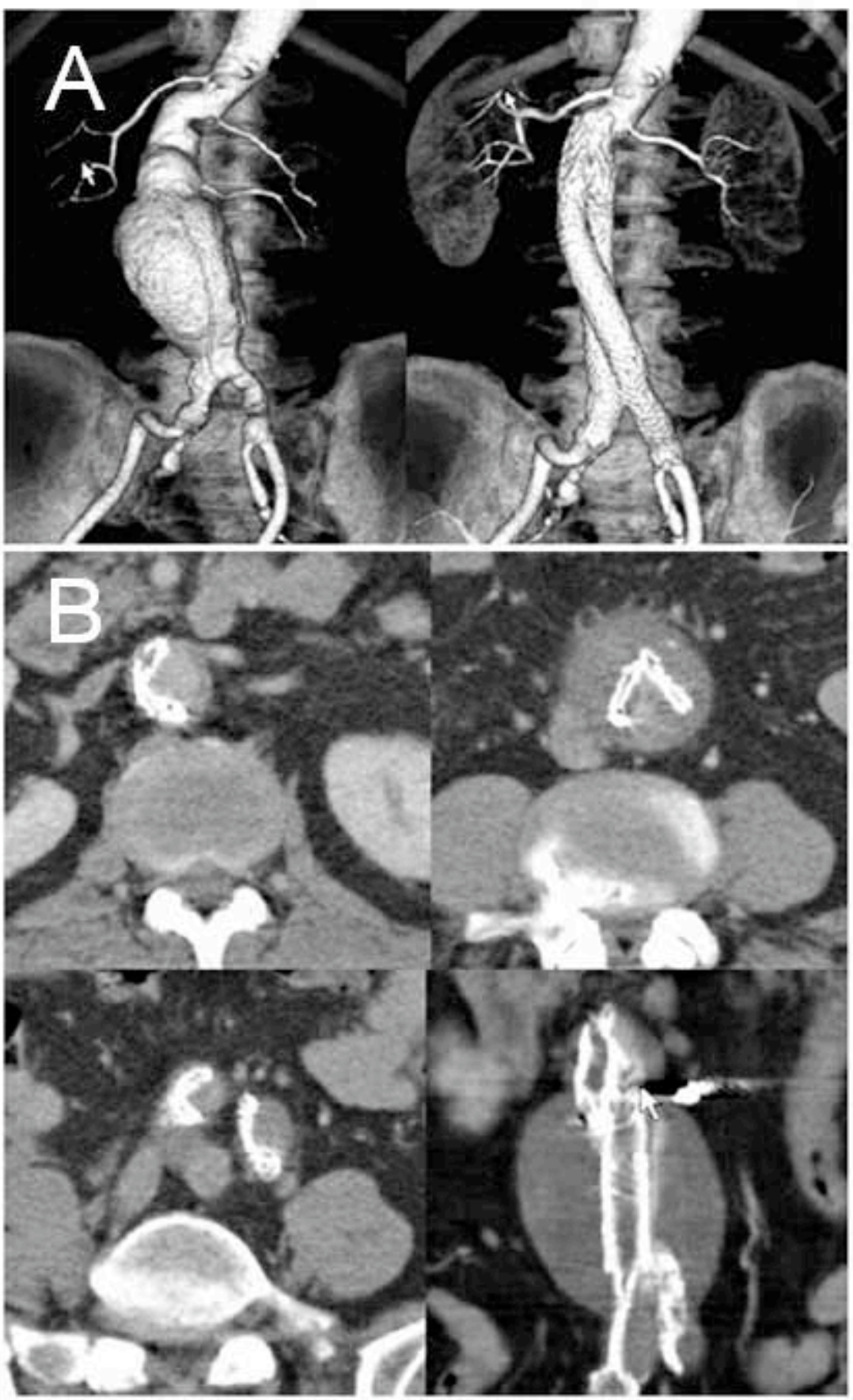

Fig. (19). Stent-graft collapse.

A. AAA with an 80-degree configuration case. The Gore Excluder ${ }^{\circledR}$ was applied in the usual manner. 3D image at discharge.

B. On the day of discharge, acute abdominal and leg ischemia occurred. CT at a local hospital showed stent-graft collapse, including the body and both stent-graft legs.

region of the main body of Excluder is placed near the lesser curvature side of the proximal neck configuration. This problem can be circumvented by placing it so that it curves ventrally or dorsally rather than in the direction of the legs.

\section{STENT-GRAFT COLLAPSE}

Although there have been reports of the collapse of TAG stent-grafts [11], no such complications have been reported for the Gore Excluder ${ }^{\circledR}$.
This report describes our experience with a case of collapse of the Gore Excluder ${ }^{\circledR}$. The patient had a sharply angled neck and was discharged from the hospital with no endoleaks after the Gore Excluder ${ }^{\circledR}$ had been inserted normally. Symptoms of acute leg ischemia developed immediately afterward, however, and the patient was brought back to the hospital for emergency repair. Fig. (19A) shows 3D images at the time of the first EVAR and upon discharge from the hospital. Fig. (19B) is a CT image taken when the patient was brought to the hospital on an 
emergency basis. The limbs had collapsed severely from the proximal part of the SG, blocking the flow of blood. The collapse was corrected by intraoperative GW insertion, and the procedure was concluded with the addition of a proximal cuff and the insertion of bare stents in both limb portions, after which CT showed no abnormality and the patient was discharged.

In such cases of sharply angled neck, graft collapse may occur as a result of blood flow. This may be because of instability in the sealing of the neck, and, in patients in whom bird-beak occurs, additional treatment, such as an extra cuff or Palmaz XL stent (Palmaz XL, Johnson \& Johnson, USA), may be required.

\section{CONCLUSIONS AND LIMITATIONS IN CLINICAL SITUATION}

Deployment in the proximal neck is an important factor for EVAR in patients in whom the IFU cannot be followed, such as those with a sharply angled neck, short neck, or shaggy aorta.

The Gore Excluder ${ }^{\circledR}$ does not have a supra-renal barb, and its main body is highly flexible, meaning it can be used to "defeat the neck" by means of the endo-wedge, scrum, wire-bend, or kilt technique, even in difficult cases.

Collapse may occur in some patients, therefore, careful monitoring is required to determine long-term outcomes in patients with sharply angled necks.

The main challenge in EVAR cases is the very large variability in the proximal neck configuration and length presented by patients in clinical situations. The commercial instructions for use, including graft size and neck length, typically do not cover all the situations encountered. Therefore, in clinical practice, preplanning is essential to determine the most effective interventional techniques to be employed.

It is our expectation that future progress in EVAR device development will address the issues, including conformation to neck configuration, discussed in this report.

\section{CONFLICT OF INTEREST}

The authors confirm that this article content has no conflicts of interest.

\section{ACKNOWLEDGEMENTS}

We would like to thank Dr. Audrius Stundzia, PhD for editing the manuscript.

\section{REFERENCES}

[1] Schanzer A, Greenberg RK, Hevelone N, et al Predictors of abdominal aneurysm sac enlargement after endovascular repair. Circulation 2011; 123: 2848-55.

[2] Maclean AA, Katzen BT. The short proximal neck. Ev Today 2006; 79-84.

[3] Leurs LJ, Kievit J, Dangnelie PC, Nelemans PJ, Buth J. EUROSTAR Collaborators. Influence of infrarenal neck length on outcome of endovascular abdominal aortic aneurysm repair. J Endovasc Ther 2006; 13: 640-8.

[4] Aburahma AF, Campbell J, Stone PA, et al. The correlation of aortic neck length to early and late outcomes in endovascular aneurysm repair patients. J Vasc Surg 2009; 50: 738-48.

[5] Grisafi JL, Rahbar R, Nelms J, et al. Challenging neck anatomy is associated with need for intraoperative endovascular adjuncts during endovascular aortic aneurysm repair (EVAR). Ann Vasc Surg 2011; 25: 729-34.

[6] AbuRahma AF, Campbell J, Stone PA, et al. The correlation of aortic neck length to early and late outcomes in endovascular aneurysm repair patients. J Vasc Surg 2009; 50: 738-48.

[7] Minion DJ, Yancey A, Patterson DE, Saha S, Endean ED. The endowedge and kilt techniques to achieve additional juxtarenal seal during deployment of the Gore Excluder endoprosthesis. Ann Vasc Surg 2006; 20: 472-7.

[8] Lee WA, Nelson PR. Sheath-assisted controlled deployment technique for Excluder bifurcated main body. J Vasc Surg 2006; 43: 1060-3.

[9] Quinones-Baldrich WJ, Chandra A. Angled guidewire delivery of aortic endovascular proetheses for angulated landing zones. Ann Vasc Surg 2009; 23: 425-77.

[10] Cochennec F, Bacquemin JP, Desgranges P, Allaire E, Kobeiter H, Roudot-Thoraval F. Limb graft occlusion following EVAR: clinical pattern, outcomes and predictive factors of occurrence. Eur J Vasc Endovasc Surg 2007; 34: 59-65.

[11] Pirotte M, Lacroix V, Astarci P, et al. Unsuccessful treatment of a collapsed thoracic stent graft by Palmatz stent. Ann Vasc Surg 2010; 24: 1137. 